\title{
Comparative Life Cycle Assessment of earth-block and conventional concrete-based houses
}

\author{
I. Papayianni, E. Anastasiou \& K. Papadopoulou \\ Laboratory of Building Materials, Department of Civil Engineering, \\ Aristotle University of Thessaloniki (AUTH), Greece
}

\begin{abstract}
The old traditional earth-block methods of construction are currently reconsidered as a very environmentally friendly alternative to modern buildings due to the advantages they provide, such as the complete recycling of materials, low energy consumption during the manufacturing process and service life, as well as the comfort and health aspects of people living in them. The weak points of earthblock structures, such as low bearing capacity and low resistance to seismic vibrations and moisture have been overcome by upgrading building materials and their behaviour using modern technology. In this paper, a comparative Life Cycle Assessment is carried out in three scenarios for a rural house in terms of Global Warming Potential. The first scenario is a conventional type of modern house with a reinforced concrete skeleton and fired clay brick masonry, the second one also has a concrete skeleton, and its only difference with the first one is the use of compressed earth-blocks instead of fired bricks, and the third one consists of a wooden skeleton and earth blocks stabilized with fly ash, so that the compressive strength of the earth-block masonry can be increased. The energy efficiency of the three houses in comparison is estimated by the following existing legislation (Energy Performance of Building Directive, EPBD) concerning the adequacy of thermal insulation of each house expressed by the final $U_{\max }$ factor $\left(\mathrm{W} / \mathrm{cm}^{2}{ }^{\circ} \mathrm{C}\right)$. In each case, the final diagrams of the $\mathrm{CO}_{2}$ eq. emissions for each scenario are given after the holistic evaluation of their environmental footprint.
\end{abstract}

Keywords: earth-block house, concrete-based house, Life Cycle Assessment.

\section{Introduction}

The availability of building materials has been a critical issue in the construction world. Historically, earth was one of the first building materials and earth masonry 
dominated for centuries in the construction of houses in certain geographical areas, such as southern Europe, the Middle East and Africa. In later years, the evolution of building technology and commerce favoured the use of fired bricks, rock, wood, cement and other building materials instead of earth-block masonry, due to their low cost and improved performance. The availability of some or all of these materials is high in most parts of the world, rendering earth-block masonry construction obsolete. On the other hand, the radical population growth and urbanization increased construction globally to a great extent and, combined with resource depletion, led to considerable environmental problems. Energy consumption and waste production must be reduced at a global scale and the construction sector is responsible for a considerable part of both (Avrami [1]). Along these lines, it can be seen that alternative constructions such as earth-block masonry, which uses low energy materials and techniques, is being reconsidered as an environmentally friendly solution.

Compressed masonry blocks are a traditional, low-strength building material (Heath et al. [2]), which currently attract interest due to their very low environmental footprint, as well as their good thermal properties (Bei [3], Papayianni et al. [4]). Their weaknesses include low bearing capacity, vulnerability to seismic vibrations and low resistance to moisture, but modern building technology has achieved the mitigation of these to a great extent. The most important technical and environmental benefits of compressed masonry blocks are complete recycling, low energy consumption for the production and during service life and high health and comfort performance, especially in hot Mediterranean climates. Additionally, among the advantages of earth building are the low costs, availability and easy workability, fire resistance, subduing extreme outdoor temperatures and maintaining a satisfactory moisture balance.

Furthermore, the combination of earth and fly ash could produce masonry blocks with good mechanical properties due to the self-cementing capacity of calcareous fly ash (Papayianni [5], Yang and Xiao [6]). The final product would have a good environmental profile, as it would provide a high volume rate of industrial by-product utilization and low energy consumption (Anastasiou et al. [7]). It is estimated that sintering accounts for $87 \%$ of the total energy required for brick production (Kalkan [8]), while energy consumption for clay extraction and drying is avoided.

In this paper, different scenarios regarding the construction of a theoretical model house made with earth-blocks are studied and compared to a conventional concrete-based house in a rural area by applying principles of energy efficiency regulations and Life Cycle Assessment (LCA).

\section{Goal and scope}

Current construction practices in Greece consider mostly reinforced concrete buildings either for urban or rural construction, while urban construction usually consists of at least three- or four-storey buildings. Taking this into account, as well as the material properties, it is considered more feasible to develop an earthmasonry block construction for single- or two-storey houses, which are usually 
located in the suburbs or in rural areas. For the purpose of the present study the theoretical house location was chosen to be outside the urban area of Thessaloniki, Greece. The goal of this comparative LCA is to evaluate the environmental impact related to three different alternatives of rural housing and the different construction methods under examination were; a conventional concrete frame house with conventional fired brick masonry according to modern construction practices; an alternative, constructed with a concrete frame and earth-block masonry; and a second alternative, an earth-block based house following the principals of traditional structure adjusted to modern life and needs.

The latter is expected to require less energy consumption during construction, mainly due to the use of compressed earth-blocks instead of fired bricks, as well as during service life and, hence, it is expected to have a decreased overall environmental impact.

\section{Materials and scenarios}

As a theoretical model for the study, a twin, two-storey house of a total $457.44 \mathrm{~m}^{2}$ was selected and placed in the suburban area of Mikra, to the east of Thessaloniki, a few kilometres away from the main urban area, under known climate conditions and orientation, capable of accommodating two families of four members, as previously described in Galanidou and Vaskou [9]. The heated area is $351.78 \mathrm{~m}^{2}$ and the heated volume $1161.825 \mathrm{~m}^{3}$. The floor height is $3.2 \mathrm{~m}$ and the pitched roof is constructed with a wooden skeleton, covered with ceramic tiles and is projected $45 \mathrm{~cm}$ around the facades of the building. The basement serves as a storehouse. A thermal insulating material protects the external sides of the building. All three house scenarios are heated with an oil boiler system. Regarding glazing and shading, identical solutions following current construction practices are considered for each of the three scenarios and, therefore, they are not taken into account in the comparative LCA.

\subsection{Conventional housing model (Scenario I)}

The term "conventional building materials" refers to widely used materials in the construction sector such as concrete, fired bricks, synthetic materials (ex. polystyrene), synthetic or wooden frames and acrylic paints.

This particular house scenario under study consisted of a concrete bearing skeleton and fired brick masonry. More specifically, the concrete slabs are $150 \mathrm{~mm}$ thick; the columns in the perimeter of the floor plan are $400 \times 400 \mathrm{~mm}$ and connected with $250 \times 600 \mathrm{~mm}$ beams. The foundation is also made of concrete. The insulation material is extruded polystyrene, $70 \mathrm{~mm}$ thick. The dimensions of the fired bricks are $60 \times 90 \times 190 \mathrm{~mm}$. The roof prolongs from the outline of the floor plan in a length of $400 \mathrm{~mm}$. The exterior walls are covered with organic coating whereas the interior walls are covered with lime cementbased coating. This model house represents the most common house in Greece. 


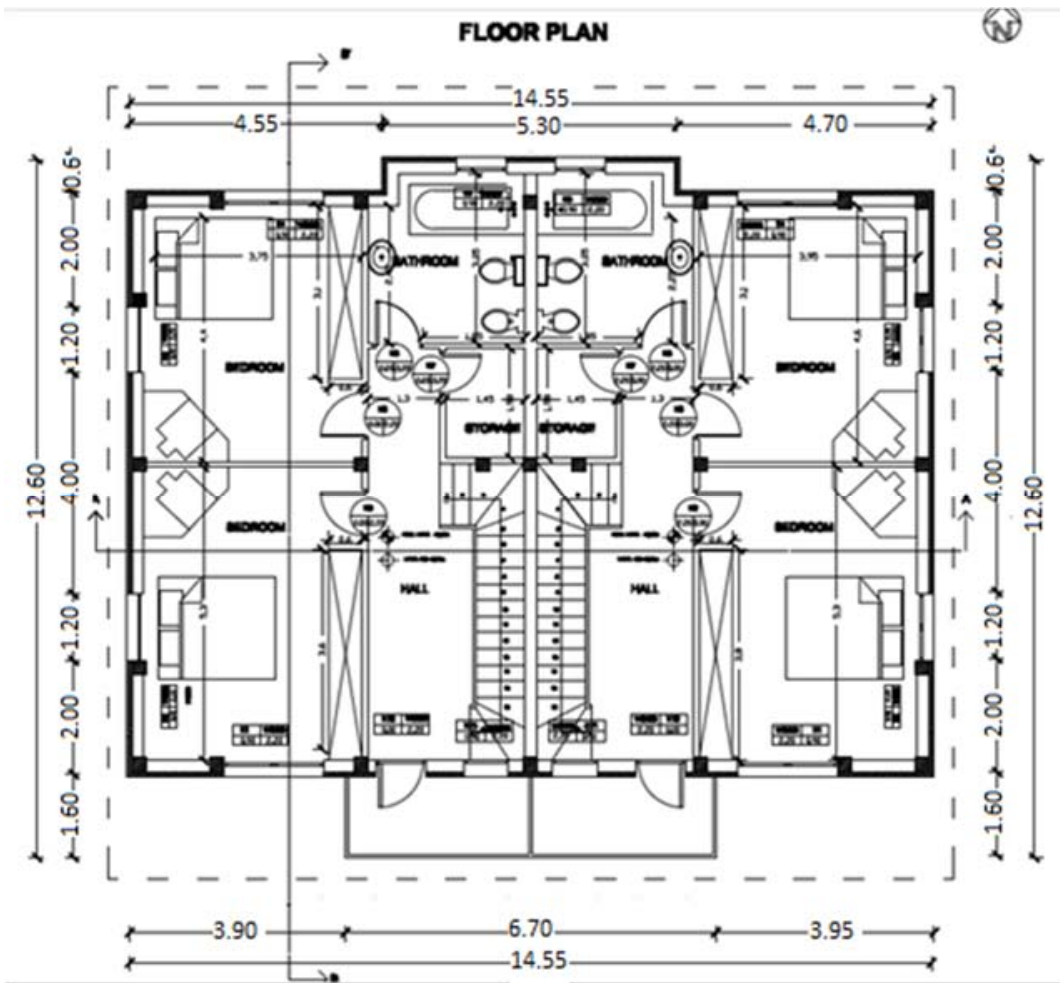

Figure 1: Floor plan of model house.

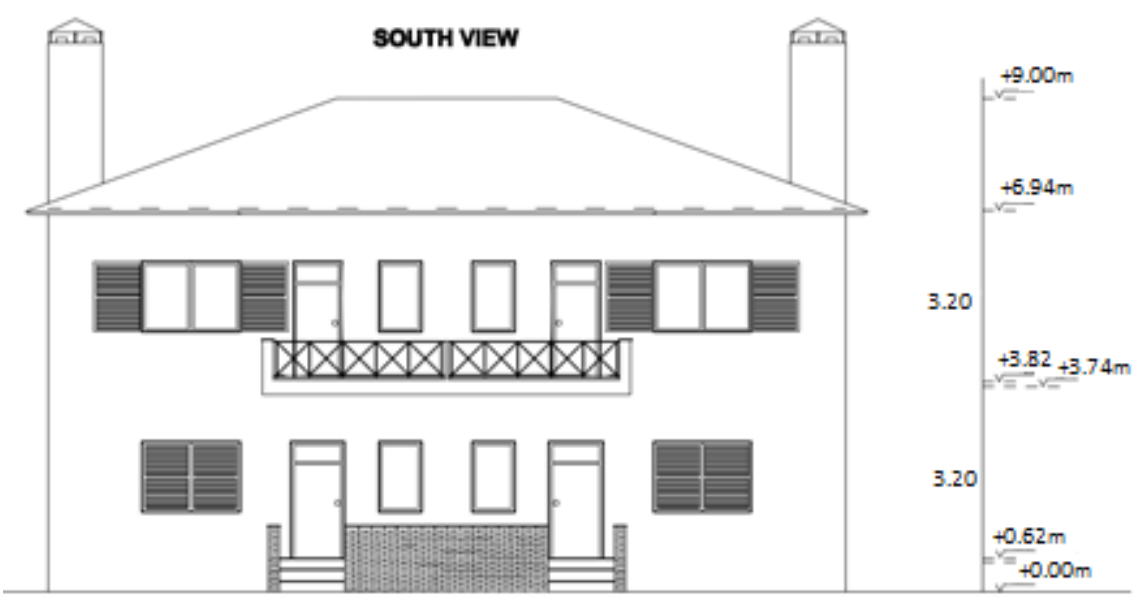

Figure 2: South view of model house. 


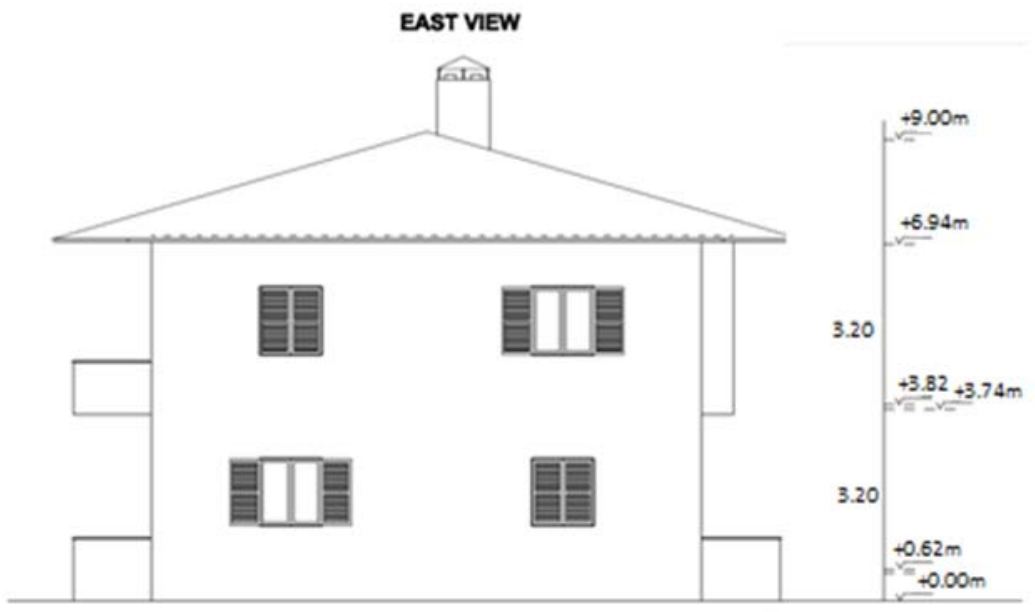

Figure 3: East view model house.

\subsection{Transitional housing model (Scenario II)}

As a transitional phase to an alternative housing scenario, the materials of the bearing skeleton were kept the same as those used in Scenario I and an innovation was attempted by replacing the fired bricks with compressed earth-blocks of the same dimensions. For a better performance of the building materials, $70 \mathrm{~mm}$ thick rockwool was chosen as the insulation.

\subsection{Alternative housing model (Scenario III)}

For reasons of better stability of the structure, the foundation was kept the same as in scenarios I and II (concrete).

The bearing skeleton consists of timber pillars $\left(250 \times 250 \mathrm{~mm}^{2}\right)$ and beams $\left(150 \times 150 \mathrm{~mm}^{2}\right)$ as well as some diagonal connections, while the masonry is made of compressed earth-blocks insulated with rockwool (Chatziastrou [10]). Both exterior and interior walls are covered with clay-based mortar of similar composition to the earth blocks.

For reasons of simplicity, some of the parameters were considered to be equal in order to simplify the comparison. For instance, the concrete foundation, the wooden frames and glass of the openings, as well as the roof and the floors, are common in all three scenarios and are not taken into account in the LCA.

\section{Life Cycle Assessment}

\subsection{Approach}

The LCA follows a cradle-to-grave approach. A life cycle inventory was compiled for all three scenarios under examination, but since the study is a comparative 
LCA, some common processes were omitted. The impact assessment used was the IPCC approach, aiming at the quantification of the Greenhouse Gas Emissions (GHG) for a time period of 100 years, following the requirements of the International Standard ISO 1404:2006 [11]. According to the IPCC 2007 GWP impact method, the corresponding Global Warming Potential (GWP) was calculated for the emitted GHG in kilograms of $\mathrm{CO}_{2}$ equivalent $\left(\mathrm{CO}_{2}\right.$ eq.) (IPCC [12]). Moreover, in order to measure the environmental load from resource use, the use of natural mineral and recovered material was determined for each scenario.

The functional unit selected is $1 \mathrm{~m}^{2}$ of horizontal surface area. This was selected as the most representative unit for houses, as their value is mostly determined by area. Also, different building materials require different sizes of structural elements and result in different required volumes of material. The required horizontal surface area, however, was constant in the three model houses.

\subsection{System boundaries}

The system boundaries include material profiles from extraction, energy required for processing and transportation of the materials to site. Also, energy consumed during the construction phase and the service life of the building was taken into account.

End-of-life scenarios were included in the system boundaries and for each scenario consider disassembly of the building and reuse of the materials as:

- Recycled Concrete Aggregates at a rate of $60 \%$ for concrete, the remaining $40 \%$ is assumed to be disposed as landfill

- $60 \%$ of the structural steel is assumed to be recycled, while the remaining $40 \%$ is disposed as landfill

- Filler at a rate of $60 \%$ for fired bricks, the remaining $40 \%$ is assumed to be disposed as landfill

- $\quad$ Clay at a rate of $100 \%$ for earth-blocks

- Wood at a rate of $70 \%$, the remaining $30 \%$ is assumed to be send to final disposal

- Insulation is assumed to be send to landfill at a rate of $100 \%$

Road transportation is assumed for all materials and different transportation distances were considered for different materials, based on actual conditions.

Concrete is assumed to be ready-mixed and the distance from the factory to the site is $15 \mathrm{~km}$. Construction steel is considered to be provided by a factory at a distance of $35 \mathrm{~km}$ from site. Fired bricks are supplied by a factory at a $55 \mathrm{~km}$ distance from site. Insulation materials are assumed to be supplied from a factory at a distance of $110 \mathrm{~km}$. Earth-blocks are assumed to be supplied by local manufacturers, $75 \mathrm{~km}$ from the construction site. Timber pillars are provided by a factory at a distance of $37 \mathrm{~km}$ from site.

For the transfer of all materials from factories to site the use of a diesel truck of $16 \mathrm{~m}^{3}$ capacity was assumed. The life cycle inventory regarding energy consumption was calculated according to the power production conditions in Greece (energy produced almost entirely by burning lignite). 


\subsection{Global Warming Potential}

The Global Warming Potential of each model under study expressed in $\mathrm{CO}_{2}$ eq. for their life cycle was calculated using the IPCC 2007 GWP 100a impact assessment method. The results are shown in Fig. 4. It is clear that as we move from Scenario I to III, replacing conventional building materials with alternative more environmentally friendly ones, there is an enormous impact on GWP. More specifically, the $\mathrm{CO}_{2}$ eq. emissions are reduced by $48.8 \%$, between Scenarios I and III, whereas replacing only the fired bricks with compressed earth-blocks reduces the $\mathrm{CO}_{2}$ eq. emissions by $7.26 \%$.

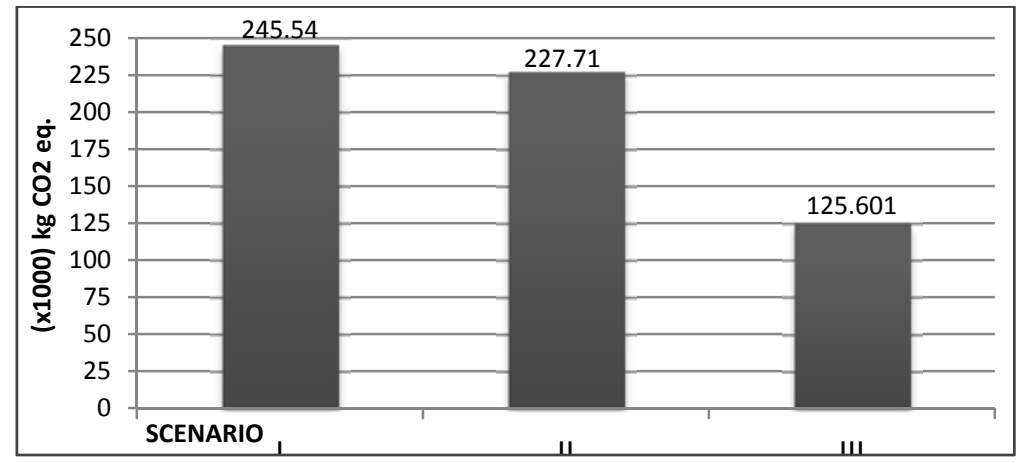

Figure 4: Life cycle Global Warming Potential for house scenarios.

Comparing the contribution of the different phases of each scenario production of building materials, construction, service life and recycling-disposal - Fig. 5 shows that the production of building materials and the construction phase are the main contributors to the GWP of the two house scenarios. However, in Scenario III there is an allocation between the production of building materials, energy during service life and recycling-disposal phases. Although the contribution of the production of building materials phase to the overall GWP seems comparable in all three scenarios, there is a significant difference between the remainder of the phases, always in favour of the alternative house scenario.

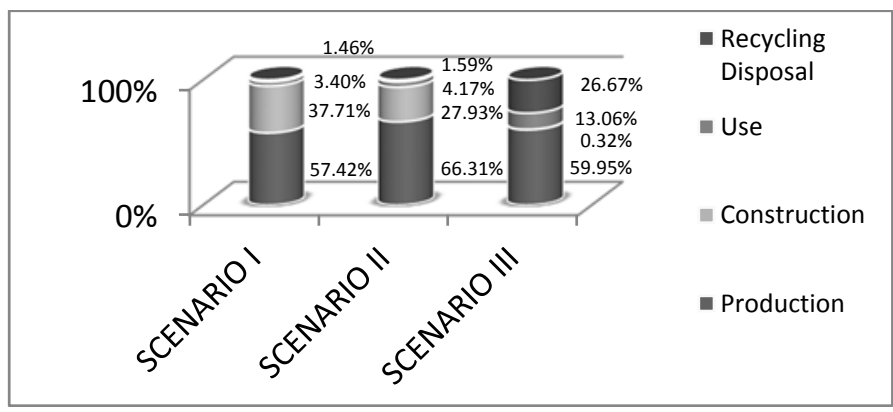

Figure 5: Process contribution to GWP for house scenarios. 


\section{Conclusions}

The present study investigates the effects of the use of alternative building materials on a theoretical rural two-storey house model. The particular type of housing was selected because it has low structural requirements and it seems there is a potential market for alternative construction solutions such as earth masonry blocks, but note, the results of the study could also be easily applied in similar urban housing.

Regarding the GWP of a single house construction, alternative environmentally-friendly building materials reduce emissions over the whole life cycle. The reduction is considerable when earth masonry blocks replace fired bricks, but is much higher when earth masonry blocks are combined with a wooden skeleton to form the frame of the house.

Conventional building materials require a considerably higher amount of energy consumption for production and construction alone. Moreover, most of them have a low recycling rate, which also explains the low impact of the recycling-disposal phase in contrast to the alternative building materials, which are recyclable at a much higher rate. Since the LCA approach had limitations, such as energy for glazing, roofing, shading, etc., the results are mostly qualitative and used for comparison purposes.

Regarding earth masonry blocks as a building material, apart from the low consumption of energy and consequently low GWP during construction, there are concerns about production, maximum performance during service life, as well as their recycling and disposal at the end of the building's life, since it is a widely unknown material to the construction market and its use is limited.

Familiarizing ourselves with the production and use of alternative building materials would render contemporary earth building with wooden skeleton and earth block masonry feasible, which in turn could infer considerable environmental and financial benefits.

\section{References}

[1] Avrami E., Sustainability and the Built Environment, Conservation Perspectives GCI Newsletter, Vol. 26, pp. 4-9, 2011.

[2] Heath A, Lawrence M, Walker P and Fourie C., The Compressive Strength of Modern Earth Masonry, Proc. of the $11^{\text {th }}$ Int. Conf. on Non-Conventional Materials and Technologies (NOCMAT 2009), Bath, UK, 2009.

[3] Bei G., Masonry Wall Construction with Earth Blocks: Research and Innovation in Greece, Proc. of the $1^{\text {st }}$ Panhellenic Conf. on Building Materials and Elements, Technical Chamber of Greece, Athens, 2008 (in Greek).

[4] Papayianni I, Axarli K, Papadopoulou K, Manolopoulou K, Vaskou M and Galanidou V., Earth-block building: An energy efficient alternative for rural Housing, Proc. of the $6^{\text {th }}$ Dubrovnik Conf. on Sustainable Development of Energy, Water and Environment Systems (SDEWES), Croatia, 2011. 
[5] Papayianni I., An investigation on the pozzolanicity and hydraulic activity of a High Calcium Fly Ash, Mag. of Concrete Research 39(138), 1928 pp., 1987.

[6] Yang J and Xiao B., Development of unsintered construction materials from red mud wastes produced in the sintering alumina process, Construction and Building Materials 22, pp. 2299-2307, 2008.

[7] Anastasiou E, Papayianni I and Avoritis M., Masonry block production using fly ash and red mud, Proc. of the $3^{\text {rd }}$ EVIPAR Conf. on Utilization of Industrial By-products in Construction, Thessaloniki: EVIPAR. 2013 (in Greek).

[8] Kalkan, E., Utilization of red mud as a stabilization material for the preparation of clay liners, Engineering Geology 87(3), pp. 220-229, 2006.

[9] Galanidou V. and Vaskou E., Life Cycle Analysis of Three House Models, Aristotle University of Thessaloniki, Greece, 2011.

[10] Chatziastrou Ch., Personal Communication, February 2013, Technical support Director at FIBRAN S.A., Thessaloniki, Greece.

[11] ISO 1404:2006. Environmental management - Life cycle assessment Principles and framework, International Standards Organisation.

[12] IPCC. IPCC Fourth Assessment Report, Cambridge University Press, Cambridge, UK, 2007. 